\title{
Transversus Abdominis Plane block to the rescue
}

\author{
MV Eeshwar ${ }^{1 *}$, Anshu Sharma ${ }^{1}$, Lokvendra Singh Budania ${ }^{2}$, Vamshidhar Chamala Reddy $^{1}$ \\ Yogesh K Gaude ${ }^{2}$, \\ Assistant Professor ${ }^{l}$, Associate Professor ${ }^{2}$, Kasturba Medical College, Manipal, India. \\ ORCID ID: 0000-0003-4138-7814
}

\begin{abstract}
Chronic kidney disease (CKD) is one of the most prevalent conditions worldwide. Patients with $\mathrm{CKD}$ require haemodialysis on a regular basis. Peritoneal dialysis is the procedure of choice for renal replacement therapy in patients with end stage renal disease (ESRD). A 43-year-old female patient, diagnosed with cardio renal syndrome (CRS) type 2 was scheduled for continuous ambulatory peritoneal dialysis catheter (CAPD) insertion. Considering the poor condition of her heart and kidneys, bilateral Transversus Abdominis Plane (TAP) block (midline incision) along with monitored anaesthesia care (MAC) was administered thus reducing the perioperative complications.
\end{abstract}

Keywords: Chronic kidney disease; cardio renal syndrome; TAP block

\section{Introduction}

There has been a considerable upsurge in the incidence of chronic kidney disease (CKD) in developing countries ${ }^{1}$; as much as $54.5 \%$ of patients at the time of presentation being diagnosed with stage 5 CKD. ${ }^{2}$ Cardio-renal syndrome (CRS) refers to conditions where acute or chronic dysfunction of either the heart or kidneys leads to the dysfunction of the other. ${ }^{3}$ CRS is of 5 types, each manifesting from a varying pathophysiology. ${ }^{4}$ Patients with CRS type 2 tend to have a chronic cardiac failure culminating in CKD or can present with coexistence of both the conditions. Patients with stage 5 CKD stand in need of dialysis. Continuous ambulatory peritoneal dialysis (CAPD) as a modality of renal replacement therapy (RRT) has an advantage of being a home-based therapy. ${ }^{5}$ CAPD insertion can be performed percutaneously or by conventional laparotomy. This imposes a considerable challenge to the anaesthesiologist. Regional anaesthesia incorporated with monitored anaesthesia care (MAC) can help prevent this perioperative stress.

*Correspondence: MV Eeshwar

E mail: eeshwar.kmc@gmail.com

https://orcid.org/0000-0003-4138-7814 Received: $19 / 09 / 2018$

Accepted:31/12/2018

DOI: http:/doi.org/10.4038/slja.v27i1.8380
Transversus abdominis plane (TAP) block is a technique used to alleviate somatic pain in the anterior abdominal wall by anaesthetizing the anterior rami of spinal nerves that run in the TAP. ${ }^{6}$ Here we describe a case in which we administered ultrasound (USG) guided TAP block along with MAC for CAPD insertion.

\section{Case report}

A 43 -year-old female patient $\left(50 \mathrm{~kg}\right.$, BMI $20 \mathrm{~kg} / \mathrm{m}^{2}$ ) presented complaining of sudden onset of breathlessness to emergency triage. She was noted to be conscious, oriented but was tachypnoeic (Respiratory rate of $24 / \mathrm{min}$ ). Her vitals were stable even though the room air saturation $\left(\mathrm{SpO}_{2}\right)$ was 90 $92 \%$. It improved to $95 \%$ with $31 \%$ venturi. Her ECG showed left ventricular (LV) strain pattern, left bundle branch block (LBBB) and left ventricular hypertrophy (LVH). (Figure 1).

\section{Figure 1}

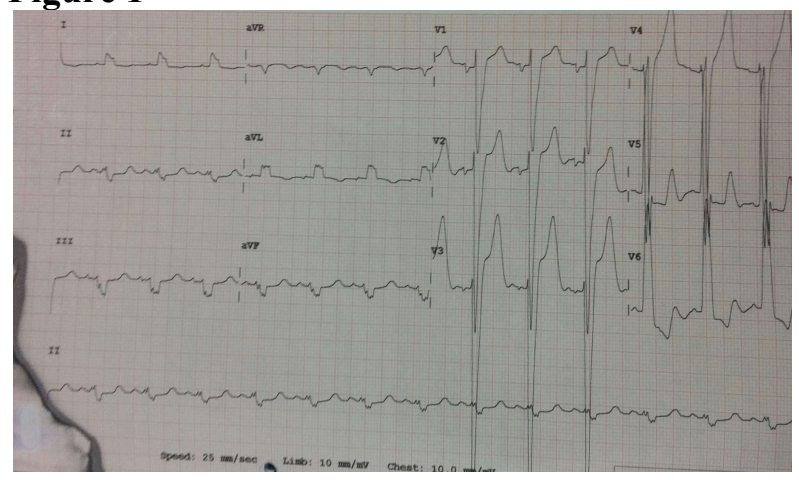


2D echocardiography showed a globally hypokinetic LV with an ejection fraction of $35 \%$. Chest $\mathrm{X}$ ray showed features suggestive of fluid overload. She was diagnosed with CRS 2. Sustained low efficiency dialysis (SLED) was provided twice before posting her for CAPD insertion. Patient underwent dialysis on the night prior and it was ensured that she was optimized before the procedure.

Her renal parameters pre and post dialysis are shown in Table 1.

Table 1

\begin{tabular}{|l|l|l|}
\hline Parameters & Pre-dialysis & Post dialysis \\
\hline SUrea & $200 \mathrm{mg} / \mathrm{dL}$ & $68 \mathrm{mg} / \mathrm{dL}$ \\
\hline SCreatinine & $6.6 \mathrm{mg} / \mathrm{dL}$ & $3.4 \mathrm{mg} / \mathrm{dL}$ \\
\hline Serum $\mathrm{Na}^{+}$ & $135 \mathrm{mmol} / \mathrm{L}$ & $133 \mathrm{mmo} / \mathrm{L}$ \\
\hline Serum $\mathrm{K}^{+}$ & $5 \mathrm{mmol} / \mathrm{L}$ & $4.5 \mathrm{mmol} / \mathrm{L}$ \\
\hline
\end{tabular}

We formulated a plan to administer bilateral TAP blocks along with MAC for this patient. Standard monitors (pulse oximeter, ECG, non- invasive blood pressure) were connected and baseline values were recorded. A working IV line was secured with provision of ongoing intravenous fluids.

Patient was positioned supine for the procedure. With strict aseptic precautions bilateral TAP blocks with $40 \mathrm{ml}$ of $0.25 \%$ levobupivacaine $(20 \mathrm{ml}$ on each side) was administered under USG guidance using a linear probe $(7-13 \mathrm{~Hz})$. (Figure 2).

\section{Figure 2}

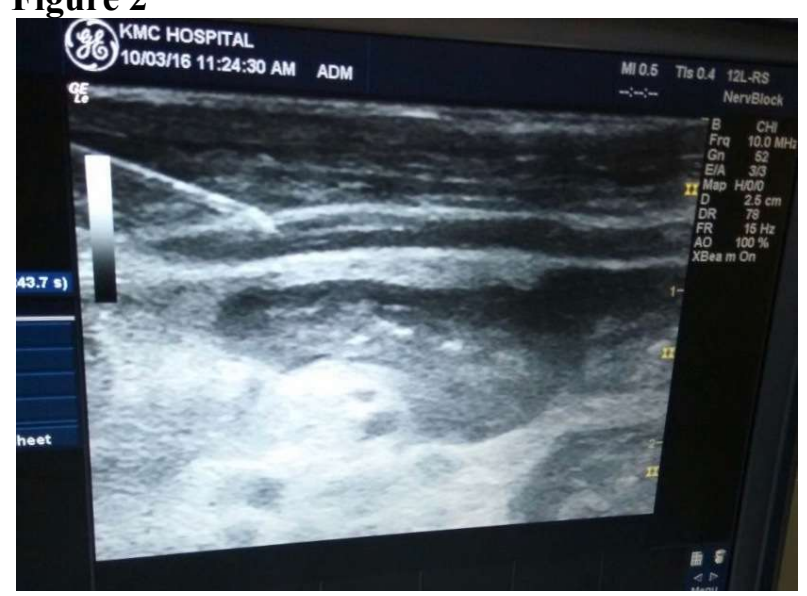

After $10-15$ minutes, first loss of thermal sensation was tested with a cold swab. Surgical forceps were used to check for pain at a later time point. Patient did not complain of pain throughout the procedure (Figure 3 ).

\section{Figure 3}

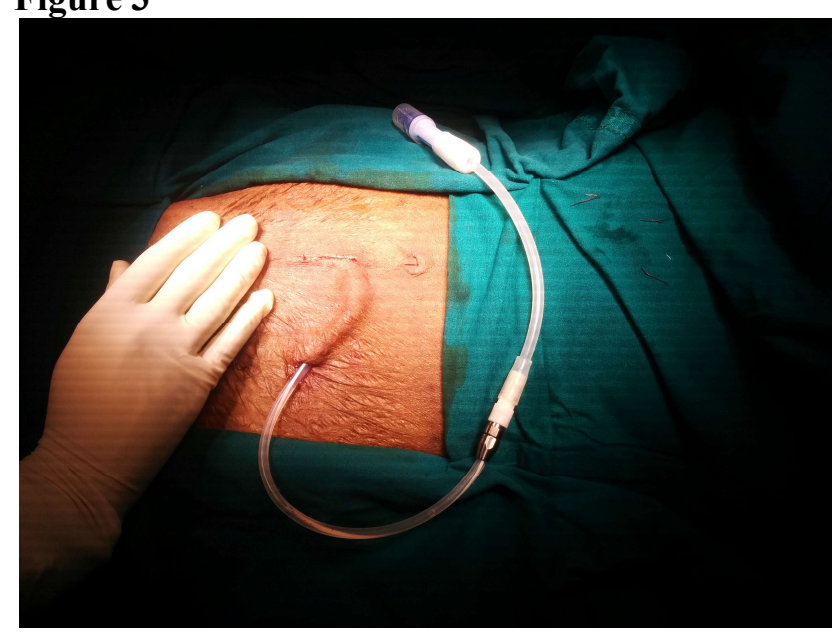

Oxygen via facemask was administered at $5 \mathrm{~L} / \mathrm{min}$ throughout the procedure. Intravenous fentanyl in the form of $1-2 \mathrm{mcg} / \mathrm{kg}$ ( $75 \mathrm{mcg})$ dosage was administered during the procedure.

\section{Discussion}

TAP block is widely acclaimed as a technique to anaesthetize the anterior abdominal wall structures. It is generally used in synchrony with general anaesthesia to provide postoperative analgesia. ${ }^{7}$ Very few cases have been reported to be performed only under TAP block without the need for additional anaesthesia. ${ }^{8-9}$ Subcostal TAP block is a modification of TAP block that spares the anterolateral region of the abdominal wall that is supplied by the lateral cutaneous branches (LCB).

Unilateral subcostal blocks have been described for CAPD insertion but needed additional infiltration with local anaesthetic and boluses of fentanyl. ${ }^{10}$

Patients with CRS predominantly present with chronic kidney disease and chronic heart failure as described above. Secondary to the chronic heart failure there is impaired perfusion to the kidneys resulting in CKD. These individuals require continuous dialysis due to kidney function impairment. CAPD is a technique also meant for domestic use. For insertion of CAPD catheter various anaesthetic techniques have been described 
including general anaesthesia, neuraxial anaesthesia, nerve blocks, thoracic paravertebral blocks, MAC and local infiltration. General and neuraxial anaesthesia can make a significant difference to the haemodynamics and complicate the anaesthetic management. Local infiltration may culminate in increased pain frequency as compared to other anaesthetic measures. Apart from choosing the ideal anaesthetic technique, we must also keep in mind the complications of CKD, which may manifest as volume overload states, metabolic disorders (acidosis), hyperkalaemia, pericardial effusions, complications related to dialysis, coagulopathy and altered drug metabolism.

TAP block along with additional dose of opioids like fentanyl are now considered safe in such patients thus reducing the stress induced by anaesthetic drugs on the already compromised cardiopulmonary reserve.

\section{Conclusion}

TAP block along with monitored anaesthesia care is an alternative for abdominal wall surgeries. It is one of the best alternatives for CAPD insertion in individuals with compromised cardiopulmonary reserve where other anaesthetic techniques are contraindicated.

\section{References}

1. Zhang L, Zuo L, Xu G et al. Community-based screening for chronic kidney disease among populations older than 40 years in Beijing. Nephrol Dial Transplant 2007;22:1093-9

https://doi.org/10.1093/ndt/gfl763

PMid:17210584

2. Varughese S, John GT, Alexander S et al. Pretertiary hospital care of patients with chronic kidney disease in India. Indian $\mathrm{J}$ Med Res 2007;126:28-33

PMid:17890820

3. Peter.PL. Can J Cardiol 2008; 24 (Suppl B): 25B $-29 \mathrm{~B}$.

PMid:18629386 PMCid:PMC2794438

4. LulloLDi, Bellasi A, Barbera $\mathrm{V}$ et al. Pathophysiology of cardio-renal syndromes types 1-5:An update. Indian Heart Journal. 2017; 69(2): $255-65$.

https://doi.org/10.1016/j.ihj.2017.01.005

PMid:28460776 PMCid:PMC5415026

5. Varughese S, Sundaram M, Basu G, Tamilarasi V, John GT. Percutaneous continuous ambulatory peritoneal dialysis (CAPD) catheter insertion - a preferred option for developing countries. Trop Doct.2010;40(2):104-05.

https://doi.org/10.1258/td.2010.090370

PMid:20305107

6. Young MJ, Gorlin AW, Modest VE, Qaurishi SA. Clinical implications of the transversus abdominis plane block in adults. Anesthesiol Res Pract 2012; 731645. https://doi.org/10.1155/2012/731645

7. Abdallah FW, Chan VW, Brull R. Transversus abdominis plane block: a systematic review. Reg AnesthPainMed.2012;37:193-209 https://doi.org/10.1097/AAP.0b013e3182429531 PMid:22286518

8. Hasan MS, Ling KU, Vijayan R, Mamat M, Chin $\mathrm{KF}$. Open gastrostomy under ultrasound-guided bilateral oblique subcostal transversus abdominis plane block: a case series. Eur J Anaesthesiol. 2011;28:888-9. https://doi.org/10.1097/EJA.0b013e32834ad9bd PMid:21857518

9. O'Connor K, Renfrew C. Subcostal transversus abdominis plane block. Anesthesia. 2010; 65: 912.

https://doi.org/10.1111/j.13652044.2009.06179.x PMid:20121788

10. 8. Yamamoto H., Shido A., Sakura S. et al. J Anesth 2016;30: 156. 